\title{
Using Participatory Action Research to Create Systematic Parent Engagement
}

\author{
Debbie Pushor \\ University of Saskatchewan \\ Canada
}

\begin{abstract}
Despite ample research supporting the value of strong family, school, and community partnerships, few districts or communities have been able to support and sustain systematic parent engagement. This article focuses on the efforts undertaken by a research team in Saskatoon, Canada to develop a model that empowers parents to systematically engage with educators and schools in order to enhance educational and social outcomes for children and parents. Central to this effort has been the use of participatory action research (PAR) as a means to honor and engage the experiences of diverse community members. This article highlights specific PAR methods that supported the development of a more systematic approach to parent engagement. The experiences described demonstrate how the improvisatory and responsive nature of the PAR approach help to both build trust and create more sustainable changes in communities.
\end{abstract}

Keywords: systematic parent engagement, participatory action research, enhanced academic and social outcomes, children, parents, and families

\section{Introduction}

Decades of research demonstrate that parent engagement ${ }^{1}$ is linked to improved academic, social, and behavioral outcomes for students and families (Brown, 2007; Hong, 2011; Mapp, 2013; National Centre for Families Learning, 2014). Despite this knowledge, in most schools parent engagement continues to be a "random act" (Weiss, Lopez, \& Rosenberg, 2010), occurring only when an individual educator values the knowledge parents hold. In this participatory action research (PAR) project, our team of stakeholders is focused on learning what supports the systematic engagement of parents with their children's teaching and learning across the landscape of schools, in out-of-school times and places, and with their own educational opportunities (e.g., language classes) in order to enhance educational and social outcomes for 
children and parents. Interested in researching both the key elements and the process conditions that are required to establish a systematic approach to parent engagement, our research questions include:

- How does the authentic and meaningful engagement of parents and family members in their children's education and schooling enhance academic achievement and other educational outcomes for students, while simultaneously addressing learning and social outcomes for parents and families?

- What partnerships, school staff and community development strategies, and schooling policy and practice changes are needed to develop a successful prototype to systematically engage parents in teaching and learning?

\section{Theoretical Approach}

The theoretical approach to this research is based on an integrated theory of family and school relations (Epstein, 2001). Underpinning this theory is the belief that schools cannot enhance student achievement and other educational outcomes for all students on their own. If schools are to narrow the achievement gap between Indigenous and non-Indigenous students, students living in contexts of poverty and those who are not, newcomer students, and students who speak English and are acculturated to Canadian schools and society, it will take a systematic approach to engaging parents and to addressing out-of-school factors that impact student learning (Bryk, Sebring, Allensworth, Luppescu, \& Easton, 2010; McDaniels, 2017; Walsh \& Murphy, 2003). Within this integrated theory, it is understood that the shared interests and influences of families and schools can be promoted through a philosophy and pedagogy of walking alongside (Pushor, 2015c, in press) lived out by schools through a systematic and comprehensive approach to parent engagement. When parents are engaged in their children's teaching and learning on the school landscape (pillar 1), in out of school places (pillar 2), and in ways that enhance their own growth and development (pillar 3), the "mutual influence of the two major environments that simultaneously affect children's learning and development" (Epstein, 2001, p. 31) are integrated and thus strengthened. This broad view of how students move, continuously, in and out of their home and school contexts recognizes that when the influential people in children's lives work together, there is a stronger contribution to their education and development (Feasey, 2017).

\section{Methodological Approach}

An integrated theory of family and school relations requires a methodological approach that is characterized by collaboration between community, staff, and academic participants at each stage of the research; mutual learning and education; and resulting educational, social, and policy action. To this end, as principal investigator I proposed to participants in our research site that we use Participatory Action Research (PAR) because it is a flexible and adaptable methodology (Bennett, 2004). While it has characteristics that define it methodologically and principles that guide its use, it is intended to be tailored by the community to meet the needs of the community (Bennett, 2004; Bergold \& Thomas, 2012; Dworski-Riggs \& Langhout, 2010; Heyman, 2011; Ozer, Ritterman, \& Wanis, 2010). This foundational premise was important to parents, staff, and research partners. PAR is structured, driven, and formed through an evolutionary and recursive spiral which includes: development of vision and relationships, data collection/analysis, action, assessment, and revision (Pahwa et al., 2015). Using PAR, participating parents and staff in the Pre-Kindergarten to Grade 8 school research site are engaged in all aspects of the research, potentially enabling boundaries within the school community to be re-shaped. Intending to bring about change in the lives of children, parents, and 
families, we are inviting school and parent community voice, designing and implementing the research with and for them as the evolutionary and recursive spiral unfolds.

Goodall and Vorhaus (2011) assert that there are a number of key features that must be put in place when enacting an approach that integrates family and school relations: a wholeschool planning process that includes a comprehensive needs analysis, the establishment of a shared vision and targeted outcomes, teacher and parent education about parent engagement, effective and committed leadership, established partnerships and multi-agency arrangements, a public awareness process, sustained support and resourcing, and ongoing monitoring, development, and review. Mapp, Carver, and Lander (2017) further suggest that there are process conditions that are also critical to ensuring that such an approach to systematic parent engagement is successful - that all efforts are linked to learning, intentional in building relationships of trust and respect between educators and parents, begin with the strengths and knowledge that parents possess, enable teachers and parents to learn with and from one another, and provide active learning opportunities to promote knowledge and skill development for parents and staff. Given the research evidence to support a theoretical approach of integrated family and school relations, we are working to use a methodological approach to the research in which these features and process conditions are honored and central.

\section{Research Origins}

My interest in parent engagement was formed when I took my oldest son, Cohen, to Kindergarten. Having been an educator for 15 years, Cohen's first year of school was my entry into experiences as a parent in relation to a school landscape. It was only at this point that I truly became awakened to the taken-for-granted hierarchy within schools in which parents have a marginal place and voice and in which they are peripheral to decisions that affect their children and/or families. Challenged by my experiences as a parent, I entered a doctoral program and conducted a narrative inquiry into the positioning of parents on school landscapes (Pushor, 2001). I followed that research with further narrative inquiries into parent engagement and leadership (Pushor \& Ruitenberg, 2005), into what a "curriculum of parents" (Pushor, 2011, 2013a, 2013b, 2014) might look like in teacher education settings, and into "parent knowledge" (Pushor, 2015a, 2015b) in order to make visible how parents, too, are holders of knowledge of children, teaching, and learning.

Twenty or so years into my research on parent engagement, I had clear understandings of what parent engagement is (and is not), what parent knowledge is and how it can be used alongside teacher knowledge to enhance policy, programming, and curricular decisions for students, and what some of the critical elements are in relation to educating teachers to work in new ways alongside families. I felt an urgency to synthesize all of these various elements into a study to explore how to embed systematic parent engagement to make a difference for children, parents, and educators. The province of Saskatchewan, Canada in which I live, is large geographically $(651,900$ square kilometres or 251,700 square miles) but small in overall population at 1.2 million people. Despite distances, there are strong connections between the provincial Ministry of Education, professional bodies such as the Saskatchewan Teachers' Federation (STF) and the Saskatchewan School Boards Association (SSBA), universities, and regional school divisions. Building on these relationships, I met with potential collaborators to discuss the establishment of a partnership to engage in research which would lead to the development of a provincial prototype for systematic parent engagement. 


\section{Partners' Table}

I felt a team approach that would harness the collaborative will, efforts, and influence of a variety of stakeholders and decision-makers in the province of Saskatchewan would enable actualization of the research plan and movement of the results and findings from research into action. To truly affect the systematic engagement of parents in teaching and learning, I believed it would take the interrelated engagement of a number of human service sectors with oversight responsibilities. As a result, I sought out partners from the following bodies:

- Ministerial level: Ministry of Education, Ministry of Social Services, Ministry of Immigration and Career Training;

- Provincial level: Saskatchewan School Boards' Association (SSBA);

- Local level: Saskatoon Public Schools (location of Howard Coad School, our research site).

In each instance, the collaborators who joined the research project are decision-makers in senior leadership positions with access to resources and supports to enhance the learning and wellbeing of children, parents, and families representative of Indigenous, newcomer, and lowSES, as well as majority Canadian, populations. As signatories to the Memorandum of Understanding (MOU) that we developed in December 2015, the collaborators form what we call the Partners' Table. They provide advice and direction to me as lead researcher, potential reallocation of resources within their organization, and the power and influence to affect decisions, which creates possibilities to achieve the outcomes of this research. When I met with them individually to negotiate the research and their role within it, and when we met collectively as a Partners' Table, we discussed their role as being one of giving us permission to "break the rules" within this prototype research, when we had sound reason to do so, in order to try something new and research the impact of the change.

The process of negotiation and establishment of the Partners' Table occurred over an intense six month period. What I believe brought partners to the table and drew their commitment was the hopefulness and possibility in doing something different. In Saskatchewan, self-declared Indigenous individuals total $16 \%$ of the population. 90,000 new immigrants have settled in the province since 2007 (Personal communication, Immigration Services, Labour Market Development Division, Ministry of the Economy). In 2014, 24.6\% of the province's children live in poverty, well above the national average of $18.5 \%$. Those percentages equate to 64,000 children (and over 160,000 people overall) (Gingrich, Hunter, \& Sanchez, 2016).

The harsh realities of these statistics are that Indigenous people and recent immigrants experience higher rates of poverty than many other sectors of the population. In Saskatchewan, just over $40 \%$ of self-declared Indigenous students are graduating from high school on time (Saskatchewan Provincial Auditor's Report, 2017), and almost half the population in Adult Basic Education classes are self-declared as Indigenous. Current school improvement efforts are not interrupting stagnant provincial student achievement rates or addressing inequities in student outcomes in schools. Workforce development, then, becomes even more important: essential for both civic engagement and quality of life. Every partner at our table recognized how imperative it is that we prototype and research new ways to address the achievement of both students and adults in our province. 


\section{Research Site}

After the signing of the MOU, which formalized the research project, the Director of Education for Saskatoon Public Schools and I met in January 2016 to discuss possible research sites. Because of the demographic profile, we decided to approach the staff and parents of Howard Coad School, a Pre-Kindergarten to Grade 8 public school in the Mount Royal neighborhood of Saskatoon, to determine if they were interested in being our research site.

The student population at Howard Coad of approximately 265 children is diverse, with approximately one third of the student population representative of a majority Canadian population, one third Indigenous, and one third newcomer. The Neighborhood Profile (City of Saskatoon, 2015) shows the labour force participation rate is more than $10 \%$ lower than that of the city, while the economic dependency ratio is more than double. The median total income in Mount Royal is listed at $\$ 29,540$. For those employed, sales and service is the primary occupation with trades, transport, and equipment operation the second highest occupation. Many parents at Howard Coad are working very hard, often with more than one job, but earning minimum levels of income. A context of poverty, low literacy rates and levels of education, English language needs, unemployment and under-employment are challenges that present themselves at Howard Coad. Given the diversity of this community, we felt that what we could learn from research in this site offered great possibility to inform a provincial prototype for the systematic engagement of parents in teaching and learning.

\section{Negotiating Entry}

We initially held meetings with the school principal and then school staff from January through March 2016 to share the intent of the research project. There was a mixed reaction to our proposal from the staff, with stated concerns from some individuals about the uncertainty of what the research would mean for them, given that it was to be a participatory action research approach and thus not one for which we could present them a pre-determined and certain research plan. In one staff meeting led by the school principal, at which no one from the research team was present, three questions were posed to the staff: What is the best thing that could happen? What is the worst thing that could happen? What else do we need to know? Staff were given pads of sticky notes and were invited to write their thoughts and post them on chart paper under the question to which they were responding.

Regarding "best things that could happen," staff identified such things as strengthening intergenerational respect, using the community's pool of knowledge, empowering students, and gaining greater resources. "Worst things that could happen" included concerns about the regulation of who comes and goes in the school building, budget demands and a need for additional funds, a potentially increased workload and time commitment, and whether parents would replace educational assistants, thus cutting union positions. In terms of what else they needed to know, staff were seeking more clarification about what their roles might be, what their work day would look like, how space would be shared in the school, and what the staging or phases of the research project would entail. This detailed input from staff enabled us to address some concerns and questions directly, and it guided further discussions about participatory action research methodology. After a series of open and sometimes challenging conversations with staff, it was determined that the decision regarding whether the school was to become the research site could be taken to parents and family members who reside within the community, and that staff would accept the decision that the community made.

We held a community forum in March 2016, to which all families were invited through a flier sent home with children, a personal phone call, and the use of the school's Remind communication tool. We provided a family dinner to over 100 individuals, childcare during the 
forum component, transportation for families who indicated that need, and interpreters for two of the main language groups, Urdu and Arabic. After a brief and plainly-worded presentation on systematic parent engagement and its benefits to approximately 40 parents, table groups, facilitated by a staff member and a parent who was a member of the School Community Council, discussed the following questions and recorded parents' responses on chart paper:

- What do you want for your children?

- What do you want for your family?

- What do you want for yourself as a parent?

- What gifts do you have to share with others in this community?

At the end of the evening, after whole-group sharing and discussion, each parent was given an exit slip on which they could indicate whether or not they would like to have a research project focused on systematic parent engagement situated at Howard Coad School, or if they had questions that they needed answered before they could decide.

Following the meeting, the School Community Council (SCC), the elected parent advisory council for the school, of which the Principal and Vice-Principal are also members, reviewed the charts completed that evening and tallied the exit slips. With all parents indicating that they wanted the research project located at their school, and with no expressions of concern, the SCC passed a unanimous motion to give the project their full support. This motion was shared with the staff and with the Partners' Table, and discussions began about how to act on what parents had voiced in that first community forum.

\section{Research Methods}

From April 2016 to the present, we have engaged in a number of methods to move our action research forward in a way that is participatory, evolutionary, and responsive to the expressed interests, desires, and talents of both the parent and staff communities. We determined early on that we would extend multiple invitations in multiple ways and that participation for everyone, including all staff, would be voluntary. We worked to consciously attend to the diversity within the community as we extended invitations and opportunities, and we specifically sought the engagement of Indigenous, newcomer, and majority Canadian children, parents, and family members. We have worked to engage parents in this research undertaking, to engage staff, and to engage parents and staff in shared processes. In each of these areas, I will highlight examples of research methods that have proven successful for us. 


\section{Engaging Parents}

Community forums. As noted above, we began our engagement with parents through a community forum. Given both the opportunity to build trust and relationships within our community and the rich data we obtained regarding the ways parents would like to engage in order to enhance opportunities for their children, themselves, and their families, we continued to host community forums throughout our research process.

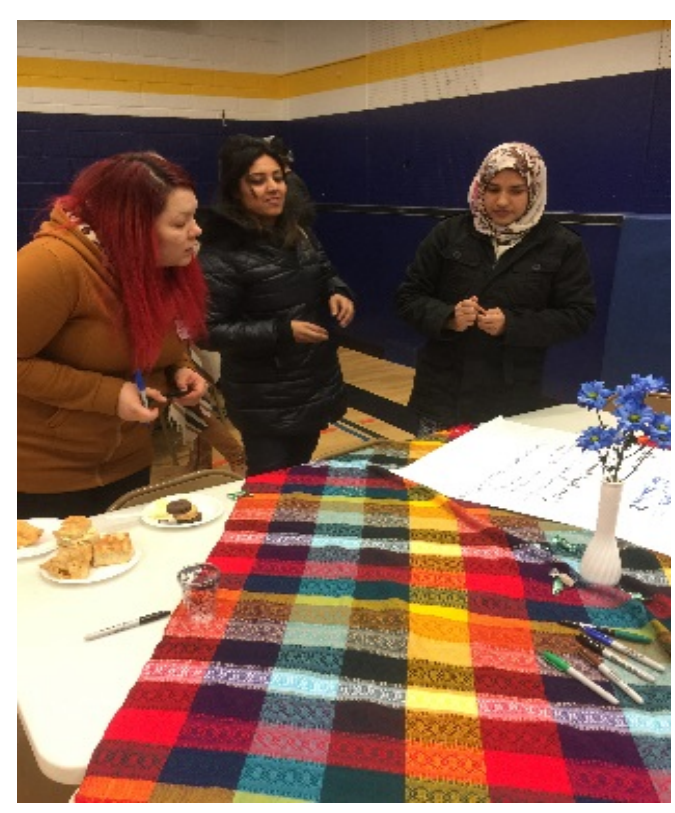

Figure 1. Table-group activity
With each forum, we invite families in multiple ways: sending information home, going doorto-door to ensure the information was received and understood and to explain the purposes of the forum further, and/or to extend personal invitations through phone calls. When we gather, we begin with a family supper (with food choices reflective of the cultural make-up of our community) served in an inviting and relaxed environment: tablecloths and flowers on the tables, children sitting with their parents during the meal (rather than being separated in a childcare space), and with ample time for families and staff to linger and visit with one another throughout the meal.

After we have eaten, we typically review progress to date and share information on resources obtained to support the work through grants, contracts, and in-kind contributions. To continue to plan forward, we facilitate conversations with staff and parents through interactive table-group activities and

end the evening with whole-group sharing. We provide childcare, transportation as requested, and we work to have translators present in order to make it possible for a wide intersection of our families to attend and participate.

The focus of our second community forum, held one year after the first, centered around an activity in which parents and staff reflected on where Howard Coad School was, in relation to Henderson, Mapp, Johnson, and Davies' (2007) four versions of partnership. On large laminated charts on the tables, everyone worked in groups to place different-colored dots by the indicators under each level of school - fortress, come-if-we-call, open-door, and partnership - to indicate elements that a) they believed were in place, b) those they were unsure about or did not know if they were in place, and c) those they desired for Howard Coad School. Parent and staff input from this activity gave us clear direction about future steps.

On a vast majority of the charts, colored dots had been placed indicating a desire for a "family center that is always open and has resources to offer families," "home visits made to every family," and "community groups offer programs at the school which are linked to learning." As a result of this input, we established a parent room in the school which we call the "family gathering place," I provided voluntary professional development to staff who then began to conduct home visits, and we entered into an agreement with Frontier College to provide an after-school homework club for students.

The third community forum, held in early November 2017, was targeted specifically for parents and families new to Howard Coad School. With a transient and growing school population, we wanted to ensure that parents new to the school had an opportunity to learn about the ongoing research on systematic parent engagement and to see a place for themselves within 
it. After sharing what we were doing and why we were doing it, we provided time for introductions and informal discussions among parents and staff at the tables. Finally, we introduced a parent survey (discussed below) and closed the evening with coffee, conversation, and connections, completing the survey with individual parents during this time.

The fourth community forum, held in January 2018 , shared a visual map of our work in systematic parent engagement, providing a schema of the input we had received from parents and staff through the community forums, and from parents through community canvassing (discussed below) and parent surveys.

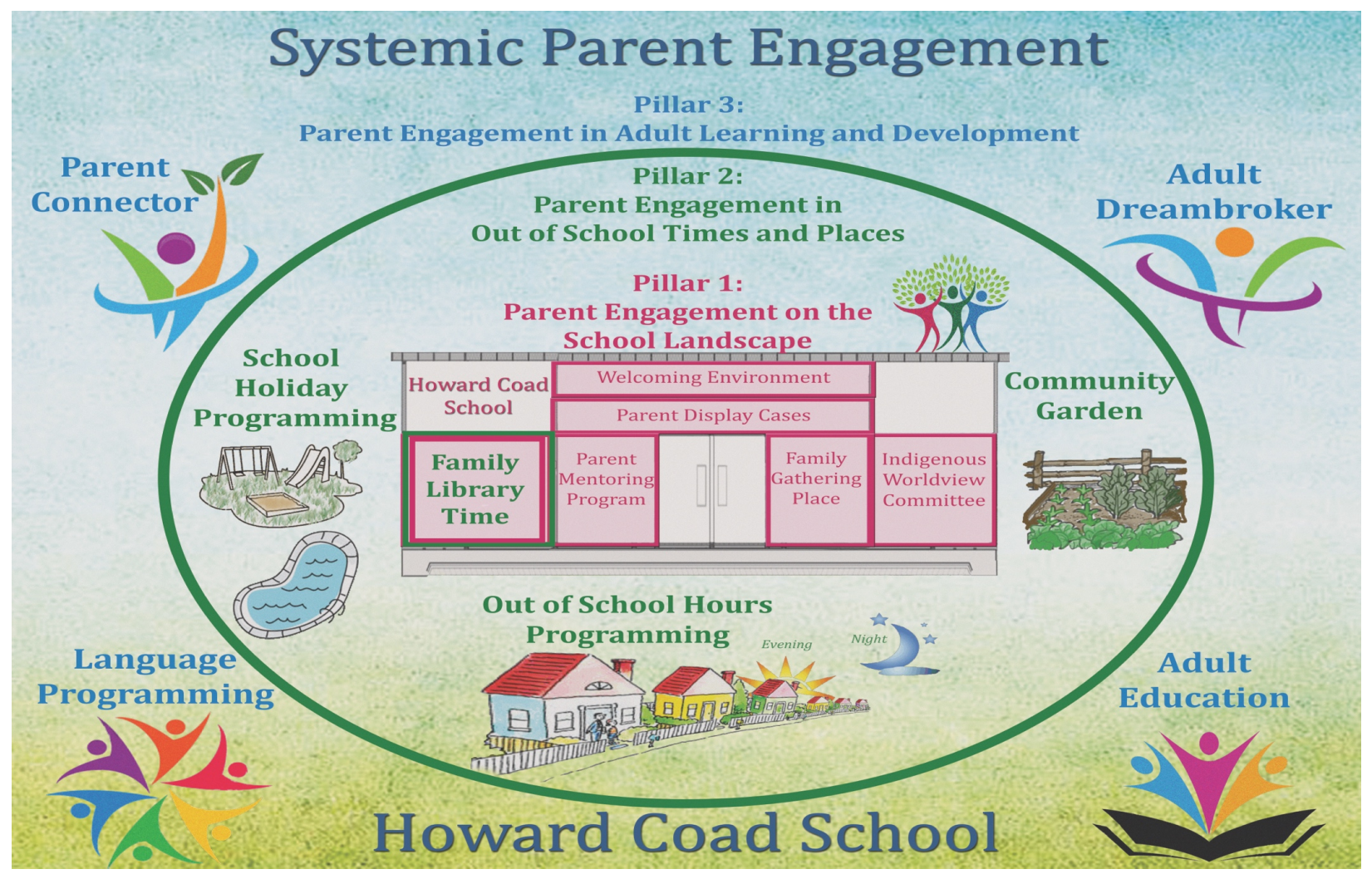

Figure 2. Visual map of community forum input.

Fourteen charts were prepared in advance, one for each of the items under the three pillars (e.g., "welcoming environment" from pillar 1). The charts were laid on tables throughout the room. Parents and staff members each took a marker and moved throughout the room, brainstorming ideas and resources that would enable us to achieve the desired outcome, responding to the ideas of others, and signing their names on items in which they would like to play a role. 
With attendance of 35-50 adults each time, the community forums have provided us an opportunity to think together as parents and staff, to look back on what we have achieved, and to move us forward toward our stated goals. They have been times which have enabled us to consider complexities we are facing and to develop clearer direction about which pathways to pursue. To provide an example, at the fourth forum, a grandfather at the school talked about how, as part of the dominant Canadian population, he would like to get to know our newcomer families better. His question was, "How do we connect across boundaries in our community?" During the work with the charts, newcomer parents saw the parent engagement display cases as an opportunity to respond to the grandfather's question. They suggested that the cases be used to profile their various home countries, cultures, and religions, with one group at a time creating a featured learning opportunity for other members of the school community.

Having done some experimentation with an activity to build social cohesion called Cooking for Cohesion, we envisioned this

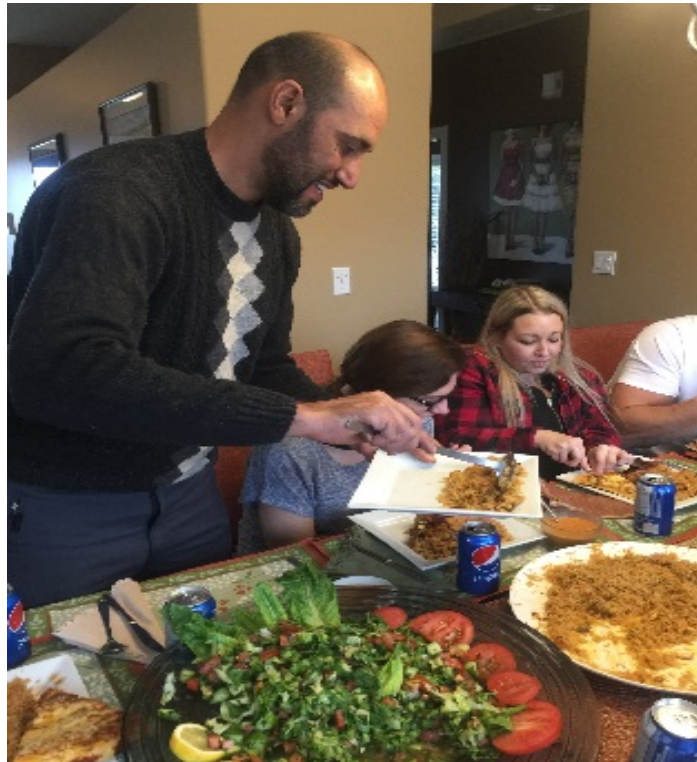

Figure 3. Cooking for Cohesion. becoming a complementary activity, corresponding with the parent engagement display cases. In Cooking for Cohesion, parents cook a meal for others, sharing information about foods and spices they typically use, special cooking techniques, and pertinent concepts such as halal products, as an example. Once the meal is ready, everyone sits together to enjoy it, and the host family tells stories of their home country, their family, what brought them to Canada, what their journey was like, what the joys and challenges of living in Canada have been for them.

What I believe this example makes visible is how the community forums have provided a place and voice for parents and staff to think together and to imagine new possibilities for family and school partnerships. To reiterate what Pahwa et al. (2015) detailed in regard to participatory action research structures, the community forums have been a place for the development of vision and relationships, data collection and analysis, decision-making, and a call to action.

Parent surveys. After our first community forum in March 2016, we were thrilled with the rich data we obtained. It was clear that parents had strong interest in the engagement opportunities, and so we decided, given that we had two months until summer break, we would move quickly to develop summer programming to be offered to children, parents, and families at the school over the holiday period. At the same time, we were aware that the data only reflected the voices of approximately 40 parents. We worked with the Social Sciences Research Laboratories (SSRL) at the University of Saskatchewan to design a parent survey which asked the same questions we asked in the first Community Forum and then followed those questions up with logistical questions about whether parents would prefer drop in or registered programs, daytime or evening offerings, weekday or weekend offerings, and so on. The survey was constructed so that it could be completed on paper or in an online format, and it was translated into three main language groups (Tagalog, Urdu, and Bengali) as well as offered in English. With 21 surveys completed, plus data from the community forum, we had enough information to 
move forward in our planning of summer programming. Nevertheless, we were aware that we were not reaching many of the families in our community. While we had representation from all three demographic groups at our first community forum, the largest number of parents in attendance were majority Canadians and most of our 21 surveys were completed in English. We also wanted to ensure we were hearing the voices of families with less attachment to the school.

A year later, in Spring 2017, we again worked with the SSRL to design a second survey, Family Needs Assessment and Community Asset Mapping, using the Voxco online platform. This time our purpose was to obtain demographic information about our specific families: family composition; children's ages; languages spoken; education levels; employment; current enrollment in English language, adult education, or trades and skills classes; relationships and connections within the community; and hopes and dreams for all family members. Cognizant that many barriers may be keeping people away from the school-language, work schedules, past experiences with school, a lack of knowledge of Canadian schooling, trust and relationships - we wanted to extend our reach within the community. In order to create a wider web of relationships, to connect with a greater number and diversity of families, and to ensure families understood why we were asking these questions and how the information they chose to share would inform the three pillars of the research project, we chose to do this survey face-toface, primarily by going door-to-door in the community.

The Parent Connector (described below), Community School Coordinator ${ }^{2}$, and I completed the survey on our cell phones as we conversed with families, with data being uploaded directly to the SSRL server. Part of our data analysis from this survey provided us with descriptive statistics on all collected measures, while another part included measures of association: whether there is a relationship between key demographic variables and parent engagement. The parent survey data has been key in giving us particular knowledge and insights into the diverse profiles of children, parents, and families within our community. We became much more aware, for example, of the number of parents who work two or three part-time jobs, working days, evenings, and weekends to earn a living; of the feelings of isolation and loneliness of non-English speaking refugee mothers with preschool children; and of the ways in which cultural and language groups are clustered geographically within the community. Gaining this insight has provided us with the opportunity to be more responsive and reflective in the planning and implementation of our research methods.

Parent Connector. To enable us to design and offer summer programming, to survey door-to-door in the community, and to help strengthen the bridge between the work of the systematic parent engagement research project and families, we obtained grant money to develop the paid role of Parent Connector. We made it a core requirement that the position be held by a parent who was a member of the school community, an individual without any formal roles or responsibilities within the school hierarchy, someone who was a peer to other parents. We defined the key responsibilities of the Parent Connector as follows:

- to work closely with parents, family and community members, and school staff to build trust and relationships;

- gain up-to-date knowledge of and insight into family contexts;

- link home learning and school learning;

- promote and support the engagement of parents in teaching and learning both on and off the school landscape;

- support school staff in making connections with families; 
- provide leadership and support in creating a welcoming and inclusive school community environment and a culturally responsive place and voice for parents in school.

Shannon deBakker, a parent in the school with one child in primary grades and one in upper elementary, and whose children had attended Howard Coad for all of their schooling, was recommended by the school principal for the position. Because Shannon spent a significant amount of time in the school landscape, she was well-known and respected by both staff and parents in the community. We felt that selecting someone for this new position who could begin her work from a place of relationship would be a strong asset. Shannon and I spent many hours meeting, in conversations about the conceptualization of parent engagement and the program of research, and, also with Lori Pulai, the Community School Coordinator, planning and implementing summer programming and community outreach. While initially Shannon built connections with families on the school landscape through the summer program offerings, phone calls, newsletters, Facebook postings, scheduled coffee times, and after school programming, as time progressed and trust and relationships deepened, she spent increasingly more time in the community and in parents' homes. As parents' trust grew with Shannon, it correspondingly grew with the school.

Community canvassing. With a belief in a familycentric (Pushor, 2015c) approach to our research, one which requires a "deeper noticing" (Bateson, 1994, p. 109) of families, we wanted to spend time in the community to truly get to know parents and families, to understand the knowledge they hold and employ, to see "the many ways in which they are engaged in educating their children - through cultural or religious teachings, experiences and activities they create for their children or in which they enroll them, their interactions with them, and the myriad of people, places and things to which they introduce them" (Pushor, 2015c, p. 248). Most often, we went into the community as learners, walking through neighborhoods, visiting with children and parents, engaging in conversations, or completing our survey. Some evenings we would complete only one survey because a family insisted we stay and have a meal with them. Other times, we might get two or three done, lingering over stories, meeting family members, viewing cultural artifacts, or holding babies or small children.

At the start of the 2017-2018 school year, the Principal scheduled a community walk for all Howard Coad staff, led by our Parent Connector. Having spent so much time in community, Shannon was able to share with staff her embodied map and knowledge of the neighborhood and of where and how our families lived within it. As children came running, shouting, "Our teacher is coming, our teacher is coming," the power of leaving the school landscape to spend time in community was palpable.

At other times, we went into the community to share information about parent engagement opportunities and to let children and parents know about events happening at the school. I recall canvassing in the community one beautiful summer evening with our Parent Connector and our School Community Coordinator, sharing information about a family literacy event, Saskatchewan Odyssey, being hosted at the school the next day by READSaskatoon. The extension of this personal invitation resulted in approximately 70 people, parents and children, engaged in literacy activities for the entire following summer afternoon.

Parent Pathfinder. Another new position created as a result of this unfolding research is that of Parent Pathfinder ${ }^{3}$. While this idea was initially conceived of by parents in our very first Community Forum as an "Adult Dreambroker" position, it has taken some time for us to garner funding for the position. The idea for the Adult Dreambroker arose from the fact that our school has a Dream Broker for children. Sask Sport Inc. is an organization which employs Dream Brokers in inner city schools: individuals who sustain the involvement and participation of innercity children and youth in existing sports, culture, and recreation activities and programs. Playing 
off of this idea, parents suggested the creation of an Adult Dreambroker to support them, different in purpose, but someone who could help them broker their dreams for enhanced language, learning, skill development, and employment opportunities.

Drawing both from parent survey data and from information shared through the Parent Connector, the core function of the Parent Pathfinder is to engage parents and family members in teaching and learning opportunities that enhance their personal and professional growth and development; literacy, language, and education levels; labour market skills and employability. The Parent Pathfinder's duties and responsibilities include:

- working closely with parents and family members, the Community School Coordinator, and the Parent Connector in engaging parents in teaching and learning opportunities, establishing and facilitating culturally responsive learning and work environments, connecting to and/or providing adult learning supports and services, and contributing to a welcoming and inclusive school community environment for adult learners.

- communicating closely with the Parent Connector in regard to parents/adults who are seeking skills and/or employment enhancement, or personal or professional growth and development opportunities.

- working collaboratively with partners, government, and community agencies to develop and support sustainable individualized adult learning, language learning, and personal and professional growth and development plans.

- $\quad$ serving as a wayfinder for parents, family and community members who are seeking work/job readiness services, support with career decision making, skills enhancement, or connections to educational or employment opportunities.

- participating as a member of the school's strategic parent engagement planning team.

To date, our Parent Pathfinder Lindsay Katz has organized a language class for parents at our school (half-days, five days per week), in response to high demand from parents who do not have transportation or childcare to get to a program elsewhere, and who are feeling socially isolated because of limited language skills. Lindsay has also worked with parents to further enhance their resumes through volunteer activities, which provide them with both relevant experiences and references for when they are ready to enter the workforce. She has established summer programming that will enable them to earn certificates such as Food Safety, Serve It Right, First Aid, and CPR, making them eligible for a wide variety of positions. Lindsay's role as Parent Pathfinder is in response to research evidence that demonstrates parents' economic, health, educational, and social contexts impact their ability to nurture and support their children's opportunities in school and in life (Davis-Kean, 2005; Donnellan, Martin, Conger, \& Conger, 2013; Lareau \& Weininger, 2003; Lee \& Bowen, 2006).

\section{Engaging Staff}

As Mapp (2013) emphasizes, with her dual-capacity building framework for familyschool partnerships, the learning and development of staff is critical to engage parents in their children's teaching and learning. Just as we sought ways to engage parents in our program of research, we also sought ways to have staff identify an integral place for themselves in this work. Given that staff members had a range of opinions about the research project and the opportunities it presented, I felt it was important to spend time with each staff member to begin to build relational trust. 
One-on-one meetings. With funds from the School Superintendent, the Vice-Principal arranged for substitute teachers for two days and created a schedule in which everyone was given the opportunity to be released from their duties for a block of time in order to meet with me individually. The staff, a group of approximately 28 individuals, represented a majority Canadian demographic, with one Indigenous teacher, one Métis teacher, and one Indigenous educational assistant. Three of the teachers were male. All but three staff members scheduled a meeting with me. During the one-on-ones, teachers or educational assistants and I chatted about our families and our career histories. We discussed questions they had about the proposed research, what more they wanted to know, what their thoughts and feelings were about the proposal, and where they potentially saw themselves within the research. In the time we had together, I felt we broke through tensions that existed, made connections, and had honest conversations with one another. I learned much about the staff - their passions, interests, previous experiences, and ideas about the research - and I feel they learned much about me as well. I left the school each of the two days excited about the conversations and with a strong sense of how individual staff members may wish to enter and participate in the unfolding participatory action research. I have always believed that "fair is not equal," and because of our conversations I began to see emerging and yet diverse entry points for various staff. For example, there were staff interested in being part of a parent mentor program, an educational assistant who wanted opportunities for professional learning about parent engagement, a resource teacher who saw possibility in working with parents to re-write core school documents in parent-friendly language, and a teacher who felt it was imperative to find ways to engage Indigenous students and families.

As research has shown, trust and relationships are a critical underpinning in home-school relations (Bryk \& Schneider, 2002; Henderson, Mapp, Johnson, \& Davies, 2007; Pushor \& Ruitenberg, 2005). I understood that my development of relationships with staff was a critical first step to engaging them in determining an unfolding research process alongside parents and in establishing a shared vision for systematic parent engagement. After the one-on-ones, I was no longer a stranger to the staff and my presence on the school and community landscape was more welcomed and understood.

Teacher education courses. The resistance that was expressed by some members of the staff at Howard Coad School about the systematic parent engagement research did not arise from malice or ill will, but instead, I believe, from a lack of knowledge of what parent engagement is and of research that demonstrates the positive impact of parent engagement on students' educational and social outcomes. With no required coursework on working with parents in teacher education programs and with parent engagement rarely being the focus of in-service professional development, it is no wonder that teachers have limited knowledge or understanding of parent engagement. To complicate this, there is often limited time on staff meeting agendas or within school professional development days and structures to create in-depth teaching and learning opportunities about parent engagement.

Believing that we cannot ask educators to work toward implementing something that they do not know or understand, I offered two for-credit university courses at Howard Coad School last year to provide a learning opportunity for those who chose to participate. I established the courses as undergraduate/graduate courses to enable everyone an entry point. Individuals without post-secondary education entered as mature students. Individuals who wanted the courses as professional learning, but did not want to work toward a degree, had the opportunity to take the courses under non-degree status. Individuals who wanted credit toward either a Bachelor of Education degree or a Master's of Education degree applied for acceptance into those programs. In the first term, eight individuals enrolled in ECUR 498/822 Re/Presenting Families in Schools: four teachers were taking the course as a beginning to their master's program, two 
teachers took the course as part of a master's program, the Community School Coordinator as a non-degree status student at the master's level, and the Parent Connector as her first postsecondary course. In the second term, 11 individuals enrolled in ECUR 411/823 Engaging Parents in Teaching and Learning, with six of the eight students continuing from Term 1 (the other two had completed their programs) and with five additional students joining us: three teachers and a principal engaged in master's coursework, and an educational assistant who was enrolled in a Bachelor of Arts program, working toward entry into a Bachelor of Education program.

Having developed these courses as part of a "curriculum of parents" (Pushor, 2013a, $2013 \mathrm{~b}$ ), and having taught them four times previous to this offering at Howard Coad, I entered them believing that certain elements were essential for the courses to impact students' beliefs and assumptions about parents and families, their knowledge about working alongside parents in strength-based and affirming ways, and their commitment to creating a place and voice for parents in the work they did with children in schools. These elements included:

- experiencing theory-students were given the opportunity to gain new or refined theoretical understandings from course readings and class presentations at the same time they were engaging in a range of lived experiences, such as participation in an Indigenous Sweatlodge, Cooking for Cohesion with a Syrian family, or eating lunch with guests at the Friendship Inn, a community centre in which vulnerable people find safe sanctuary;

- learning with parents and families-

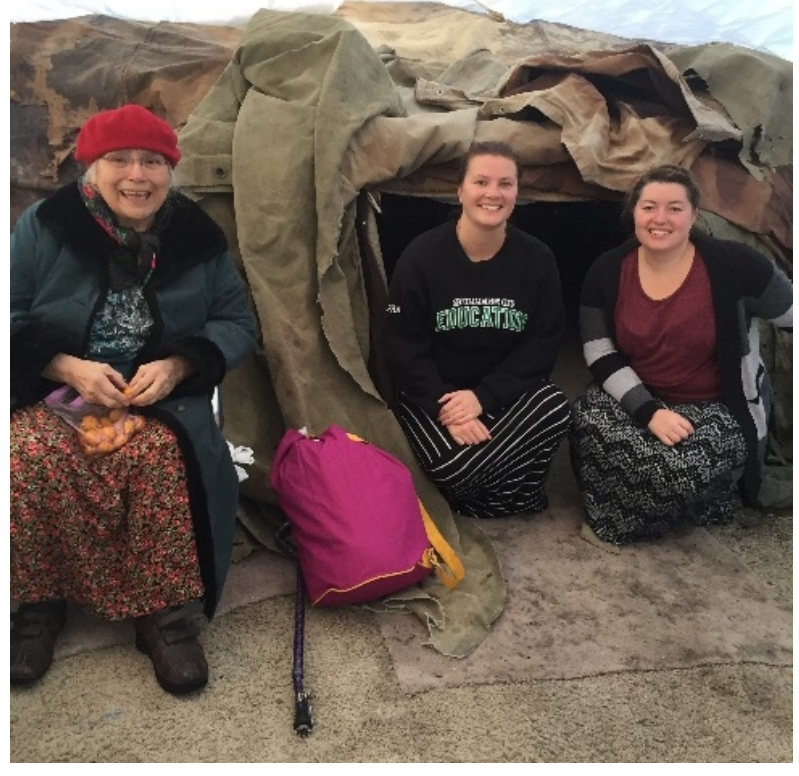

Figure 4. Learning with parents and families. students were brought together with parents and family members to learn with and from them, hearing the stories of an Indigenous father who raised his children in a core neighborhood or of mothers who raised their children in a context of poverty, coming to understand the powerful parent knowledge and insight all parents possess;

- investing personally-students were asked to "look inward" (Pushor \& Ruitenberg, 2005), to who they are, to what shaped them and why, as they shared family artifacts with one another or wrote "Where I'm From" poems (Christensen, 2001; Lyon, 1999), learning that this work is as much about them as it is about families;

- putting the learning into practice-students were asked to complete assignments in which they had to rethink taken-for-granted practices and to apply what they had learned in the specificity of their own context; for example, replacing parent-teacher conferences with opportunities to create scrapbooks of learning with students and families or to do home visits. 
As staff members engaged in this learning, they took up the research on systematic parent engagement in new ways. They became strong advocates for the place and voice of parents, sharing stories of their experiences or new insights at staff meetings, challenging colleagues' assumptions about families when comments about children or families were made in the staffroom, participating fully in community forums alongside parents, initiating new practices with families in their classrooms and in the school more broadly, and advocating for the provision of time to do home visits with families. These staff members became leaders within the participatory action research in new ways, both in regard to their actions and their influence.

\section{Engaging Parents and Staff Together}

The most challenging part of the research, in terms of methods, has been to determine when and how to bring parents and staff together for strategic visioning and planning. Time appears to be a resource in short supply for everyone.

Strategic planning table and action teams. After the first community forum and first summer of programming, as we entered into a new school year in 2016-2017, we formed a strategic planning table at the school level, through voluntary participation, comprised of members of the parent community, the School Community Council, and the staff, as well as partners from supporting community organizations who had played a part in summer programming and had made a commitment to work with us into the future. The intent of the strategic planning table was to bring together a group of individuals to develop a structure to guide the vision created through the participatory action research. It was then determined that the strategic planning table would break out into four action teams, corresponding with clusters of recommendations/suggestions which had come forward from parents and staff in regard to the systematic engagement of parents in teaching and learning.

As a group of approximately 20 individuals, we met monthly, beginning with supper at about 5:30 pm, followed by some brief professional development on parent engagement (as requested by the group), some whole-group planning and discussion, and then smaller-group work time as we broke out into the four action teams: 1) Library/Literacy/Language, 2) Health \& Wellness, 3) Parent Place \& Voice, and 4) Trades \& Skills. Work done at the strategic planning table and in the corresponding action teams was shared with the broader community at staff meetings, School Community Council meetings, and through school communications such as newsletters, fliers, and the school's Facebook page.

While the work was moving forward, participants of the strategic planning table and some parents and some staff, expressed concern about the time commitment that was required, for meetings and for corresponding work outside of meetings. Further, the sense of ownership for the research remained primarily with the members who had voluntarily joined the strategic planning table rather than emanating outward among staff and the parent community, as was intended.

Strategic vision and committee structure. The following year, 2017-2018, with a new School Principal, Jaime Schroeder, and Vice-Principal, Amy Basaraba, forming the administrative team at Howard Coad School, we revisited our guiding structures and proceeded in a revised way. As noted earlier, the Parent Connector led the staff on a community walk at the start of the school year and the administrative team allocated time for whole-school professional development on parent engagement. Jaime and Amy also ensured that parent engagement became a more regular item on staff meeting agendas, and they wrote it more comprehensively and visibly into the school's continuous improvement plan. With the visuals for systematic parent engagement developed (shown above), including the desired action items for pillars 1, 2, and 3 , those became the focus of community forum discussions and administration began to 
more consciously shape the efforts of staff, the School Community Council, and parents in relation to systematic parent engagement.

A monitoring team emerged, comprised of the School Superintendent, School Principal and Vice-Principal, the Community School Coordinator, our Parent Connector and Parent Pathfinder, the School Counselor at times, and myself as Principal Investigator. We met regularly throughout this past school year to discuss our progress in relation to targeted outcomes, discuss next steps, and monitor and/or develop resources and supports. Now, as we move once again into summer break in July 2018, we have plans for a retreat to give ourselves uninterrupted time to reflect together, to do some analysis and interpretation of our newest data, and to once again assess our progress, revising our plans and our methods to achieve them as we do so. The evolutionary and recursive process of participatory action research enters another new spiral.

Because the intention of PAR is that it is tailored to the needs of the community, by the community, our approach has necessarily evolved as school leadership and teaching staff have changed, as parent membership of the School Community Council has changed, and as participants' understanding of systematic engagement has grown. What we have seen is that because the parent community is heterogeneous and continuously evolving, so too must the design of the PAR project. Contextual issues, such as those noted above, inform the degree to which parents are able to fully engage with the research process. Different parents take lead roles in different ways and at different times. Certainly we have learned that there is not one way to do community-engaged research, but that it exists on a spectrum with context driving relational and structural dynamics. It is this organic nature of the research that makes it such an exciting and challenging methodological approach.

\section{Closing Thoughts}

So often when I find myself reflecting on, or writing about, my life's work, my research life, I am drawn back to the thinking of anthropologist and writer, Mary Catherine Bateson. Understanding life as an improvisatory art, Bateson (1989) attends closely to context, interaction, response (p. 2), to complexity (p. 4), texture (p. 5), multiplicity, and ambiguity (p. 10). She focuses not on what is composed but instead on the act of composing $(1989,2000)$, on the overlapping patterns of participation and observation, and the "interwoven disciplines of curiosity and respect" (2000, p. 18).

The participatory action research in which we are engaged, and the methods within it, reflect our attempts at Howard Coad School to improvise, to attend respectfully to the multiplicity of positions, perspectives, emotions, and ways of knowing within our school and community, to be curious about interactions and responses, our own and others, and to compose, co-compose, and re-compose a research journey that makes a difference to children, to parents and families, and to teachers. Sharing our uncertainty, what we have given you "are not the stories of daunting success, achievements so impressive and final that they are hard to identify with but the repeatable stories of composing and improvisation" (p. 31).

Over the past two and a half years at Howard Coad School much has changed. Many teachers are doing home visits, parent mentors are working with teachers in classrooms, language programming for parents is happening on the school landscape during the day, the school library is open one evening a week and on Sunday afternoons, and it includes books for babies and preschool children, as well as adults. As we look to next year, and the year after that, there is much still to compose. As parent engagement continues to become instilled as a philosophy and a pedagogy, we hope that rules of school as we know them now will be broken: that report cards and parent-teacher interviews will no longer be the way that parents and 
teachers communicate, that teachers' extracurricular time will be spent in engaging with parents as well as children, that home visits will become commonplace in teacher practice. Immersed in improvisatory research, we will continue to compose methods that enable us to fit together what we know with what we are willing to learn (Bateson, 2000, p. 18) in order to systematically engage parents in teaching and learning.

Acknowledgements: We would like to gratefully acknowledge that this research has been made possible through research grants from the College of Education, University of Saskatchewan; Saskatchewan School Boards Association; Saskatchewan Literacy Network; and the Social Sciences and Humanities Research Council of Canada (SSHRC). It has been further supported through partnership contributions, both monetary and in-kind, from the signatories to the Memorandum of Understanding (MOU). We have also benefitted from rich programmatic support from community organizations: Saskatoon Public Library; Saskatoon Community Youth Arts Programming (SCYAP); Child Hunger Education Program (CHEP); Saskatoon Food Bank and Learning Centre; Frontier College; READ Saskatoon; Saskatoon Open Door Society; and Run, Jump, Throw, Wheel. 
Using Participatory Action Research to Create Systematic Parent Engagement

\section{References}

Bateson, M. C. (1989). Composing a life. New York, NY: PLUME, published by the Penguin Group (An authorized reprint of a hardcover edition published by the Atlantic Monthly Press.)

Bateson, M. C. (1994). Peripheral visions: Learning along the way. New York, NY: HarperCollins Publishers.

Bateson, M. C. (2000). Full circles, overlapping lives. New York, NY: Random House.

Bennett, M. (2004). A Review of the literature on the benefits and drawbacks of participatory action research. First Peoples Child \& Family Review, l(1), 19-32.

Bergold, J. \& Thomas, S. (2012). Forum: Qualitative research. Participatory research methods: A methodological approach in motion, 13(1), 1-23.

Brown, J. (2007). Parents building communities in schools. Voices in Urban Education, 26, 4553.

Bryk, A. S. \& Schneider, B. (2002). Trust in schools: A core resource for improvement. New York, NY: Russell Sage Foundation.

Bryk, A. S., Sebring, P. B., Allensworth, E., Luppescu, S., \& Easton, J. Q. (2010). Organizing schools for improvement: Lessons from Chicago. Chicago, IL: University of Chicago Press.

Christensen, L. (2001). Where I'm from: Inviting students' lives into the classroom. In B. Bigelow, B. Harvey, S. Karp, \& L. Miller (Eds.), Rethinking our classrooms, Vol. 2: Teaching for equity and justice (pp. 6-10). Milwaukee, WI: Rethinking Schools.

City of Saskatoon (2015). Neighborhood profile: Mount Royal. Saskatoon, SK.

Davis-Kean, P. E. (2005). The influence of parent education and family income on child achievement: The indirect role of parental expectations and the home environment. Journal of Family Psychology, 19(2), 294-304.

Donnellan, M. B., Martin, M. J., Conger, K. J., \& Conger, R. D. (2013). Economic distress and poverty in families. In A. Fine \& F. D. Fincham (Eds.), Handbook of Family Theories: A Content Based Approach, 338-355. New York, NY: Routledge/Taylor \& Francis Group.

Dworski-Riggs, D., \& Day Langhout, R. (2010). Elucidating the power in empowerment and the participation in participatory action research: A story about research team and elementary school change. American Journal of Community Psychology, 45, 215-230.

Epstein, J. L. (2001). School, family, and community partnerships: Preparing educators and improving schools. Boulder, CO: Westview Press.

Feasey, S. M. (2017). Schools, family and community: Overlapping spheres of influence. The road less travelled. Retrieved from https://theroadlesstravelledby.com/2017/09/28/schoolsfamilies-and-community-overlapping-spheres-of-influence/

Gingrich, P., Hunter, G. \& Sanchez, M. (2016). Child and family poverty in Saskatchewan. Regina, SK: Social Policy Research Centre, Faculty of Social Work, University of Regina.

Goodall, J. \& Vorhaus, J. (2011). Review of best practice in parental engagement. UK:

Department of Education. 
Henderson, A. T., Mapp, K. L., Johnson, V. R. \& Davies, D. (2007). Beyond the bake sale: The essential guide to family-school partnerships. New York, NY: The New Press.

Heyman, A. (2011). An exploration of factors which may influence how teachers perceive participatory action research tools being employed in schools. International Journal of Social Research Methodology, 14(5), 369-378.

Hong, S. (2011). A chord of three strands: A new approach to parent engagement in schools. Cambridge, MA: Harvard Education Press.

Lareau, A. \& Weininger, E. B. (2003). Cultural capital in educational research: A critical assessment. Theory and Society, 32(5-6): 567-606.

Lee, J. S. \& Bowen, N. K. (2006). Parent involvement, cultural capital, and the achievement gap among elementary school children. American Educational Research Journal, 43(2), 193-218.

Lyon, G. E. (1999). Where I'm from. Where I'm from, where poems come from. Spring, TX: Absey and Co, Inc.

Mapp, K. (2013). Partners in education: A dual capacity-building framework for family-school partnerships. Washington, DC: Southwest Educational Development Laboratory.

Mapp, K., Carver, I. \& Lander, J. (2017). Powerful partnerships: A teacher's guide to engaging families for student success. New York, NY: Scholastic Inc.

McDaniels, A. (2017). Wraparound services: The next phase of education reform. Retrieved from

http://www.realcleareducation.com/articles/2017/09/26/wraparound_services_the_next_phas e_of_education_reform_110207.html?utm_source=rced-today

manual\&utm_medium=email\&utm_campaign=mailchimpnewsletter\&utm_source $=\mathrm{RC}+$ Education + Today\&utm_campaign $=37432673 \mathrm{~b} 1-$ EMAIL_CAMPAIGN_2017_09_26\&utm_medium=email\&utm_term=0_8a051b373b$374326 \overline{7} 3 \mathrm{~b} 1-8380669 \overline{7}$

National Centre for Families Learning. (2014). Family engagement brief. Louisville, KY. Retrieved from http:/www.familieslearning.org/pdf/NCFL_Family_Engagement_Brief_.pdf

Ozer, E. J., Ritterman, M. L., \& Wanis, M. G. (2010). Participatory action research (PAR) in middle school: Opportunities, constraints, and key processes. American Journal of Community Psychology, 46, 152-166.

Pahwa, P., Abonyi, S., et al. (2015). A community-based participatory research methodology to address, redress, and reassess disparities in respiratory health among First Nations. BioMed Central Research Notes, 8(199), 1-11.

Pushor, D. (In press). Using parent knowledge to enhance teaching and learning experiences in schools for children and youth. In T. A. Turner-Vorbeck \& S. Sheldon (Eds.), Handbook of family, school, community partnerships in education. Hoboken, NJ: John Wiley \& Sons.

Pushor, D. (2015a). Conceptualizing parent knowledge. In D. Pushor and the Parent Engagement Collaborative II (Eds.), Living as mapmakers: Charting a course with children guided by parent knowledge (pp. 7-19). Rotterdam, NL: Sense Publishers.

Pushor, D. (2015b). Mapping parent knowledge. In D. Pushor and the Parent Engagement Collaborative II (Eds.), Living as mapmakers: Charting a course with children guided by parent knowledge (pp. 20-41). Rotterdam, NL: Sense Publishers. 
Pushor, D. (2015c). Walking alongside: A pedagogy of working with parents and family. In C. Craig \& L. Orland-Barak (Eds.), International Teacher Education: Promising Pedagogies (Part B) (pp. 233-253). Bingley, UK: Emerald Group Publishing Ltd.

Pushor, D. (2014). Teachers' narrative understandings of parents: Living and reliving "possible lives" as professionals. Journal of Family Diversity in Education, 1(1), 40-57.

Pushor, D. (2013a). Bringing into being a curriculum of parents. In D. Pushor and the Parent Engagement Collaborative (Eds.), Portals of promise: Transforming beliefs and practices through a curriculum of parents (pp. 5-19). Rotterdam, NL: Sense Publishers

Pushor, D. (2013b). Planning and living a curriculum of parents. In D. Pushor and the Parent Engagement Collaborative (Eds.), Portals of promise: Transforming beliefs and practices through a curriculum of parents (pp. 21-55). Rotterdam, NL: Sense Publishers

Pushor, D. (2011). Attending to milieu: Living a curriculum of parents alongside teacher candidates. In J. Kitchen, D. Ciuffetelli Parker \& D. Pushor (Eds.), Narrative inquiries into curriculum making in teacher education (pp. 217-238). Bingley, UK: Emerald Group Publishing Limited.

Pushor, D. (2001). A storied photo album of parents' positioning and the landscape of schools. (Unpublished doctoral dissertation) University of Alberta, Edmonton, AB.

Pushor, D., Ruitenberg, C., with co-researchers from Princess Alexandra Community School. (2005, November). Parent engagement and leadership. Research report, project \#134, Dr. Stirling McDowell Foundation for Research into Teaching, Saskatoon, SK.

Walsh, M. E. \& Murphy, J. (2003). Children, health, and learning: A guide to the issues. Westport, CT: Praeger.

Weiss, H. B., Lopez, E. L. \& Rosenberg, H. (2010). Beyond random acts: Family, school, and community engagement as an integral part of education reform. Boston, MA: Harvard Family Research Project.

\footnotetext{
Notes

${ }^{1}$ While many researchers in the field have shifted to the use of the term 'family engagement,' I have consciously chosen to stay with the term 'parent engagement.' For me, 'parent' names a particular role in a family, one which is defined by responsibility, sole or shared, for the provision of acts of caregiving. I believe it is important to name this role because of its special significance within a family. Other members of a family such as children and youth, differently from a parent, are in roles that are predominantly more care-receiving than caregiving. I also believe it is important to name the role of parent because of its special significance within a school. It is a parent who is expected to sign the report card of a child or adolescent, to attend that individual's parent-teacher conference, to excuse an absence, or to participate in developing an individualized educational plan. To use the word 'family' then, in such instances, both obscures the unique roles, responsibilities, and relationships of various members within a family and the complex relationship between parents and teachers.

The term 'parent' names a role, and the term 'to parent' names acts or actions fulfilled by individuals in that role. Correspondingly, then, many different individuals, in the various family forms that exist within our society, parent. The list is broad-ranging and inclusive. Parents are persons in biological or non-biological relationships with a child or adolescent; they are grandparents or other family members; they are individuals in relationship with family members; they are workers in group homes, detention centers, and hospitals; they are significant in the lives of children and youth through fostering, adoption, or combined families. In using the term 'parent,' a particular role within a family is recognized for its distinct and significant contribution, and for being a position that generates unique parent knowledge. (Pushor, in press)
} 
${ }^{2}$ A Community School Coordinator is a designated role within schools that have a high Indigenous population and are located in neighborhoods with a complex context of poverty and its related factors. The role includes working closely with parents, students, staff, community members, volunteers, businesses, and agencies in inspiring learning, developing a community school plan, implementing and coordinating community-based programs and community education initiatives.

${ }^{3}$ Parent Pathfinder is the new name we are using for our Adult Dreambroker. See pillar 3, Systematic Parent Engagement. 